\title{
ĐÁNH GIÁ THỰC TRẠNG SỨC KHỎE - DINH DƯỡNG CỦA CÁN Bộ THUộC DIỆN TỈNH ỦY TỈNH THÁI BÌNH QUẢN LÝ NĂM 2019
}

\section{Trần Khánh Thu*, Lê Thị Thanh Phương**, Trần Mạnh Hà***}

\section{TÓM TẮT}

Nghiên cứu nhằm đánh giá tình trạng dinh dưỡng của các cán bộ thuộc diện Ban thường vụ Tỉnh ủy tỉnh Thái Bình quản lý. Đối tượng được điều tra bao gồm các cán bộ đương chức và các cán bộ đã nghỉ hưu. Thiết kế nghiên cứu mô tả cắt ngang điều tra 800 cán bộ. Đánh giá tình trang dinh dưỡng bằng chỉ số khối cớ thể (BMI), chỉ số WHR và xét nghiệm định lượng Hemoglobin máu, Albumin huyết thanh, Cholesterol máu, Triglycerid, LDL-cholesterol, HDL-cholesterol. Kết quả cho thấy tỉ lê̂ CED chung là $0,6 \%$. Tỉ lệ thừa cân béo phì chung là $14,4 \%$, tỷ lệ thừa cân nữ là $7,3 \%$ thấp hơn nam là $15,8 \%$. Tỷ lế cán bộ có nguy cơ thừa cân, béo phì tính theo chỉ số vòng eo/vòng mông là $43,1 \%$, trong đó cán bô nữ là $44,5 \%$ cao hơn cán bộ nam là 42,8\%. Nhóm cán bộ có sức khỏe phân loại Bi cao nhất chiếm tỷ lệ $88,9 \%$, loại $A$ chiếm $7,1 \%$, loại B2 chiếm $3,2 \%$, İoại $C$ chiếm $0,8 \%$. Chî số Albumin huyết thanh trung bình là $43,6 \pm 4,6 \mathrm{~g} / \mathrm{l}$; Protein huyết thanh trung bình là $70,0 \pm 8,1 \mathrm{~g} / \mathrm{l}$, Glucose máu trung bình là $6,7 \pm 1,5 \mathrm{mmol} / \mathrm{l}$. Chỉ số Cholesterol máu trung bình là $5,29 \pm 0,66 \mathrm{mmol} /$; chỉ số Triglycerid máu trung bình là $2,26 \pm 0,9 \mathrm{mmol} / \mathrm{l}$; chi số H-DLC trung bình là $1,96 \pm 0,68(\mathrm{mmol} / \mathrm{l})$. L-DLC là $2,91 \pm 0,56 \mathrm{mmol} / \mathrm{l}$.

Tư khoá: Tinh trạng dinh dưỡng, chỉ số khối cơ thể, phân loại sức khỏe, xét nghiệm máu.

\section{SUMMARY \\ NUTRITIONAL STASTUS OF THE OFFICERS UNDER THE MANAGEMENT OF THE THAI BINH PROVINCIAL STANDING COMMITTEE \\ Objective: The study aimed to assess the nutritional status of the officers under the management of the Thai Binh Provincial Standing Committee. Subjects: Surveyed included 800 incumbent officials and retired officials. Method: The epidemiological method described by a cross-sectional investigation. Evaluate nutritional status by body mass index BMI, WHR, Blood test indicators: Serum Albumin, Cholesterol, Triglycerides, LDL-cholesterol, HDL-cholesterol. Results: The results showed that the prevalence of overall CED was $0.6 \%$. The prevalence of overall overweight was $14.4 \%$, The prevalence of overweight in women $(7.3 \%)$ was lower than that of men $(15.8 \%)$. The percentage of officials at risk of being overweight based on the WHR index was $43.1 \%$, of which female was $44.5 \%$ higher than}

*Bênh viện đa khoa tỉnh Thái Bình,

**Ban bảo vệ chăm sóc SK cán bộ tỉnh Thái Bình

***Đai hoc Y Dước Thái Binh

Chịu trách nhiệm chính: Trân Khánh Thu

Email: khanhthuh@gmail.com

Ngày nhân bài: 19.8.2021

Ngày phản biên khoa hoc: 11.10.2021

Ngày duyệt bài: 21.10 .2021 male was $42.8 \%$. Health classified as B1 had the highest rate of $88.9 \%$, type $A$ was $7.1 \%$, type B2 was $3.2 \%$, type $C$ was $0.8 \%$. Albumin was $43.6 \pm 4.6 \mathrm{~g} / \mathrm{l}$; Protein was $70.0 \pm 8.1 \mathrm{~g} / \mathrm{l}$, Glucose was $6.7 \pm 1.5$ $\mathrm{mmol} / \mathrm{l}$, Cholesterol is $5.29 \pm 0.66 \mathrm{mmol} / \mathrm{l}$; Triglyceride was $2.26 \pm 0.9 \mathrm{mmol} / \mathrm{l} ; \mathrm{H}-\mathrm{DLC}$ was $1.96 \pm 0.68$ (mmol /l); L-DLC was $2.91 \pm 0.56 \mathrm{mmol} / \mathrm{l}$.

Keywords: BMI, WHR, CED, Overweight, , Health classified, Albumin, Triglycerid, Cholesterol, H-DLC, L-DLC.

\section{I. ĐẶT VẤN ĐỀ}

Trong nhiều năm qua tai Viêt Nam, sư thay đổi về kinh tế, văn hóa, xã hội đang chuyển biến tích cực, đời sống nhân dân ngày càng được nâng cao do đó sự thay đổi về mô hình bệnh tật. Hiện nay, tỷ lệ thiếu dinh dưỡng đã giảm xuống đáng kể. Tuy nhiên tỷ lệ các bệnh mạn tính như thừa cân béo phì, đái tháo đường, tăng huyết áp, bệnh tim mạch... xu hướng ngày càng gia tăng. Các nhà khoa học đã cảnh báo rằng "Thế kỷ 21 là thế kỷ của các bệnh nội tiết, rối loạn chuyển hóa" [9] và gánh nặng của các bệnh mạn tính không lây nhiễm gặp chủ yếu ở các nước có thu nhập trung bình và thấp [4].

Tại địa bàn tỉnh Thái Bình, đội ngũ cán bộ trong nhiều năm qua tình hình chăm sóc sức khỏe cán bộ được Lãnh đạo tỉnh đăc biệt quan tâm. Tỉnh đã chỉ đạo và tạo điều kiện, đầu tư mọi mặt cho công tác bảo vệ, chăm sóc sức khỏe cán bộ diện Tỉnh ủy quản lý. Hệ thống y tễ của Ban BVCSSKCB tỉnh được nâng cấp, năng lực chuyên môn nghiệp vư được nâng cao. Việc thu thập được nhiều số liệu sức khỏe sẽ giúp cán bộ y tế trong Ban có cái nhìn tổng thể về sức khỏe các cán bộ trong tỉnh.

Việc tiến hành nghiên cứu về đánh giá tình hình sức khỏe của các đối tượng cán bộ thuộc diện Tỉnh ủy quản lý và đánh giá hiệu quả thực hiện một số biện pháp can thiệp nhẳm nâng cao sức khỏe cán bộ sẽ mang lại các số liệu, bằng chứng khoa học thực tiễn góp phần cải thiện giảm biến chứng, giảm tử vong, tăng tuổi thọ, nâng cao chất lượng cuộc sống cho các đối tượng cán bộ của tỉnh. Vì vậy chúng tôi tiến hành nghiên cứu nhằm mục tiêu đánh giá thực trang sức khỏe - dinh dưỡng của cán bộ thuộc diện Tỉnh ủy quản lý năm 2019.

II. ĐỐI TƯỢNG VÀ PHƯƠNG PHÁP NGHIÊN CỨU

2.1 Đối tượng nghiên cứu. Là cán bộ thuộc diện Ban Thường vụ Tỉnh ủy Thái Bình 
quản lý gồm hai nhóm đối tượng: Cán bộ đương chức và cán bộ nguyên chức.

Tiêu chuẩn loại trứ: Loại trừ các cán bô không đồng ý tham gia, những cán bộ > 80 tuổi, trong tình trạng cấp cứu, có biến chứng nặng, không có khả năng tham gia.

\subsection{Phương pháp nghiên cứu}

Nghiên cứu được thiết kế theo phương pháp nghiên cứu mô tả qua cuộc điều tra cắt ngang.

\subsection{Cỡ mẫu và cách chọn mẫu}

*Cõ̃ mẫu: $\mathrm{n}=\frac{\mathrm{Z2}(1-\mathrm{a} / 2)}{\mathrm{e} 2}$

Trong đó: $\mathrm{n}$ : cõ mẫu cần thiết.

Z: là giá trị tương ứng của hệ số giới hạn tin cậy đỏi hỏi, với độ tin cậy là $95 \%$ thì Z(1-a/2) = 1,96.

p: Tỷ lệ đối tượng thiếu năng lượng trường diễn ước tính dựa vào nghiên cứu trước là 32,3\%

$q=1-p$

e: là sai số mong muốn, lấy e $=5 \%$.

Vậy theo công thức tính cõ mẫu thì số đối tượng cho một nhóm sẽ là 350. Như vậy số mẫu nghiên cứu của đề tài là 700 người. Trền thực tế nghiên cứu được 800 cán bộ.

* Cách chọn mẫu: Toàn bộ số cán bộ thuộc diện tỉnh ủy quản lý hiện tại là 1368 người (bao gồm nhóm đương chức có 359 người và nhóm nguyên chức là 1009 người). Như vậy với số cán bộ đương chức chúng tôi chọn tất cả 359 người, nhóm nguyên chức cũng sẽ được chọn tất cả (trừ những trường hợp quá cao tuổi hoặc vắng mặt vào thời điểm nghiên cứu hoặc không đồng ý tham gia nghiên cứu).

2.3 Phương pháp thu thập số liệu. Cân nặng của đối tượng được thu thập bằng cân điện tử Tanita của Nhật Bản có độ chính xác $0,01 \mathrm{~kg}$. Kết quả được đọc theo đơn vị kilogram và ghi tới một chữ sổ thập phân. Đo chiều cao đứng của bệnh nhân bằng thước Microtoise của Pháo có độ chính xác tới milimet. Sử dụng bản tiêu chuẩn phân loại sức khỏe cán bộ theo quyết định số 2136/QĐ-BYT ngày $15 / 6 / 2005$. Lấy máu xét nghiệm: Lấy $5 \mathrm{ml}$ máu tĩnh mạch vào buổi sáng (từ 8-10 giờ), bệnh nhân nhịn ăn và không uống bất kỳ một loại nước giải khát nào để làm xét nghiệm. Xét nghiệm sinh hóa máu trên máy Randox Imola của Nhật. Xét nghiệm huyết học trên máy Celltak-alpha 6410 của Nhật. Hóa chất xét nghiệm đều do hãng Boehringer cung cấp. Các kỹ thuật cân đo, xét nghiệm đã được chuẩn hóa.

2.5 Xử lý số liệu. Làm sạch số liệu trước khi nhập vào máy vi tính. Sử dụng chương trình Epidata để nhập số liệu và phân tích số liệu bằng chương trình SPSS 16.0 bằng các test các test thông kê y học.

\section{KẾT QUẢ NGHIÊN CỨU}

\section{Bảng 3.1. Đặc điểm về giới tính và nhóm tuổi của đôi tượng nghiên cứu}

\begin{tabular}{|c|c|c|c|c|c|c|}
\hline \multirow{2}{*}{ Nhóm tuổi } & \multicolumn{2}{|c|}{ Nam (n =663) } & \multicolumn{2}{c|}{ Nữ $(\mathbf{n = 1 3 7 )}$} & \multicolumn{2}{c|}{ Chung (n = 800) } \\
\cline { 2 - 7 } & SL & \% & SL & \% & SL & \% \\
\hline$\leq 65$ tuối & 346 & 52,2 & 80 & 58,4 & 426 & 53,2 \\
\hline$>65$ tuối & 317 & 47,8 & 57 & 41,6 & 374 & 46,8 \\
\hline
\end{tabular}

Kết quả bảng 3.1 cho thấy tỷ lệ cán bộ từ 65 tuối trở xuống chếm $53,2 \%$ trong đó, nữ giới là $58,4 \%$, nam giới là $52,2 \%$; tỷ lệ cán bộ trên 65 tuổi chiếm 46,8\%, trong đó cán bộ nam là 47,8\%, nữ là $41,6 \%$.

Bảng 3.2. Tình trạng dinh dưỡng theo giới tính dựa vào BMI

\begin{tabular}{|c|c|c|c|c|c|c|c|}
\hline \multirow{2}{*}{$\begin{array}{l}\text { Tình trăng dinh } \\
\text { dưỡng }\end{array}$} & \multicolumn{2}{|c|}{$\operatorname{Nam}(1)(n=663)$} & \multicolumn{2}{|c|}{ Nữ $(2)(n=137)$} & \multicolumn{2}{|c|}{ Chung $(n=800)$} & \multirow{2}{*}{$\mathrm{p}(1,2)$} \\
\hline & $\mathbf{S L}$ & $\%$ & $\mathbf{S L}$ & $\%$ & $\mathbf{S L}$ & $\%$ & \\
\hline Suy dinh dưỡng & 5 & 0,8 & 0 & 0,0 & 5 & 0,6 & \\
\hline & 553 & 83,4 & 127 & 92,7 & 680 & 85,0 & $<0,05$ \\
\hline Thừa cân/ Béo phì & 105 & 15,8 & 10 & 7,3 & 115 & 14,4 & \\
\hline
\end{tabular}

Kết quả bảng 3.2 cho thấy: Tỷ lệ suy dinh dưỡng ở cán bộ theo giới tính dựa vào BMI là $0,6 \%$, trong đó tỷ lệ suy dinh dưỡng bệnh nhân nam là $0,8 \%$, không có cán bộ nữ giới suy dinh dướng. Tỳ lệ thửa cân, béo phì là $14,4 \%$, tỷ lệ thừa cân nữ là $7,3 \%$ thấp hơn nam là $15,8 \%$, sự khác biệt có ý nghĩa thống kê với $p<0,05$.

Bảng 3.3. Tình trạng dinh dướng theo nhóm tuổi dựa vào BMI

\begin{tabular}{|c|c|c|c|c|c|c|c|}
\hline \multirow{2}{*}{$\begin{array}{l}\text { Tình trạng } \\
\text { dinh dưỡng }\end{array}$} & \multicolumn{2}{|c|}{$\begin{array}{c}\leq 65 \text { tuối (1) } \\
(n=426)\end{array}$} & \multicolumn{2}{|c|}{$\begin{array}{c}>65 \text { tuối (2) } \\
(\mathrm{n}=374)\end{array}$} & \multicolumn{2}{|c|}{$\begin{array}{c}\text { Chung } \\
(n=800)\end{array}$} & \multirow[t]{2}{*}{$p(1,2)$} \\
\hline & $\mathbf{S L}$ & $\%$ & $\mathbf{S L}$ & $\%$ & $\mathbf{S L}$ & $\%$ & \\
\hline Suy d & 1 & 0,2 & 4 & 1,1 & 5 & 0,6 & \\
\hline Bình thường & 351 & 82,4 & 329 & 88,0 & 680 & 85,0 & $<0,05$ \\
\hline Thừa cân/ Béo phì & 74 & 17,4 & 41 & 11,0 & 115 & 14,4 & \\
\hline
\end{tabular}


Phân loại tình trạng dinh dương tại bảng 3.3 theo nhóm tuổi cho thây có $0,6 \%$ bệnh nhân suy dinh dưỡng, trong đó tỷ lệ bệnh nhân nhóm tuổi trên 65 tuổi suy dinh dưỡng là 1,1\% cao hơn nhóm bệnh nhân từ 65 tuổi trở xuống là $0,2 \%$. Tỷ lệ thừa cân/béo phì ở hai nhóm tuổi là $14,4 \%$, sự khác biệt có ý nghĩa thống kê với $p<0,05$.

Bảng 3.4. Tình trạng dinh dưỡng theo chỉ số vòng eo/vòng mông

\begin{tabular}{|c|c|c|c|c|c|c|c|}
\hline \multirow[t]{2}{*}{ Tình trạng dinh dưỡng } & \multicolumn{2}{|c|}{$\begin{array}{c}\text { Nam (1) } \\
(n=663)\end{array}$} & \multicolumn{2}{|c|}{$\begin{array}{c}\text { Nữ (2) } \\
(\mathrm{n}=137)\end{array}$} & \multicolumn{2}{|c|}{$\begin{array}{c}\text { Chung } \\
(n=800)\end{array}$} & \multirow[t]{2}{*}{$p(1,2)$} \\
\hline & $\mathbf{S L}$ & $\%$ & SLL & $\%$ & $\mathbf{S L}$ & $\%$ & \\
\hline Bint & 379 & 57,2 & 76 & 55,5 & 455 & 56,9 & \\
\hline Có nguy $\mathrm{c}$ & 284 & 42,8 & 61 & 44,5 & 345 & 43,1 & , U, \\
\hline
\end{tabular}

Kết quả bảng 3.4 cho thấy tỷ lê cán bô có nguy cơ vòng eo/vòng mông chiếm $43,1 \%$, trong đó cán bộ nữ là 44,5\% cao hơn cán bộ nam là $42,8 \%$, sự khác biệt không có ý nghĩa thống kê với $p$ $>0,05$.

Bảng 3.5. Phân loại tình trạng sức khỏe theo giới tính

\begin{tabular}{|c|c|c|c|c|c|c|c|}
\hline \multirow{2}{*}{$\begin{array}{l}\text { Tình trang } \\
\text { dinh dưỡng }\end{array}$} & \multicolumn{2}{|c|}{$\operatorname{Nam}(1)(n=663)$} & \multicolumn{2}{|c|}{$N \tilde{u}(2)(n=137)$} & \multicolumn{2}{|c|}{ Chung $(n=800)$} & \multirow{2}{*}{$\mathrm{p}(1,2)$} \\
\hline & SL & $\%$ & SL & $\%$ & SL & $\%$ & \\
\hline Loại A & 43 & 6,5 & 14 & 10,2 & 57 & 7,1 & \multirow{4}{*}{$<0,05$} \\
\hline Loại B1 & 593 & 89,4 & 118 & 86,1 & 711 & 88,9 & \\
\hline Loại B2 & 22 & 3,3 & 4 & 2,9 & 26 & 3,2 & \\
\hline Loại C & 5 & 0,8 & 1 & 0,7 & 6 & 0,8 & \\
\hline
\end{tabular}

Kết quả bảng 3.5 cho thấy tỷ lệ cán bô sức khỏe loại $\mathrm{B} 1$ cao nhất chiếm tỷ lê $88,9 \%$, loai $\mathrm{A}$ chiếm $7,1 \%$, loại $\mathrm{B} 2$ chiếm 3,2\%, loại C chiếm 0,8\%, không có sự khác biệt về tình trạng sức khỏe của cán bộ nam và nữ với $p>0,05$.

Bảng 3.6. Giá trị trung bình một số chỉ số xét nghiệm hóa sinh

\begin{tabular}{|c|c|c|c|c|}
\hline Các chỉ số & $\operatorname{Nam}\left(\frac{1}{X}\right)(\mathbf{n}=663)$ & $\begin{array}{c}\mathbf{N} \tilde{u}(\mathbf{2})(\mathbf{n}=137) \\
X_{ \pm} \mathrm{SD}\end{array}$ & $\frac{\text { Chung (n = 800) }}{X_{ \pm} \pm \mathrm{SD}}$ & $p(1,2)$ \\
\hline Albumin máu $(\mathrm{g} / \mathrm{l})$ & $43,7 \pm 4,6$ & $43,1 \pm 4,6$ & $43,6 \pm 4,6$ & $>0,05$ \\
\hline Protein $(\mathrm{g} / \mathrm{l})$ & $70,6 \pm 7,4$ & $67,0 \pm 10,3$ & $70,0 \pm 8,1$ & $<0,001$ \\
\hline Glucose $(\mathrm{mmol} / \mathrm{l})$ & $6,7 \pm 1,5$ & $6,6 \pm 1,6$ & $6,7 \pm 1,5$ & $>0,05$ \\
\hline Cholesterol $(\mathrm{mmol} / \mathrm{l})$ & $5,30 \pm 0,67$ & $5,20 \pm 0,60$ & $5,29 \pm 0,66$ & $>0,05$ \\
\hline Triglycerid $(\mathrm{mmol} / \mathrm{l})$ & $2,28 \pm 0,94$ & $2,18 \pm 0,69$ & $2,26 \pm 0,90$ & $>0,05$ \\
\hline $\mathrm{H}-\mathrm{DLC}(\mathrm{mmol} / \mathrm{l})$ & $1,95 \pm 0,69$ & $2,00 \pm 0,63$ & $1,96 \pm 0,68$ & $>0,05$ \\
\hline L-DLC (mmol/l) & $2,93 \pm 0,56$ & $2,81 \pm 0,55$ & $2,91 \pm 0,56$ & $<0,05$ \\
\hline
\end{tabular}

Kết quả bảng 3.6 cho thấy chỉ số Albumin máu trung bình là $43,6 \pm 4,6 \mathrm{~g} / \mathrm{l}$, Protein trung bình là $70,0 \pm 8,1 \mathrm{~g} / \mathrm{l}$, cán bộ nam cao hơn cán bộ nữ có ý nghĩa thống kê với $p<0,001$, Glucose máu trung bình là $6,7 \pm 1,5 \mathrm{mmol} / \mathrm{l}$. Chỉ số Cholesterol là $5,29 \pm 0,66 \mathrm{mmol} ;$ chỉ số Triglycerid là 2,26 \pm $0,9 \mathrm{mmol} / \mathrm{l} ;$ chỉ số H-DLC là $1,96 \pm 0,68(\mathrm{mmol} / \mathrm{l})$, không có sự khác biệt giữa nam và nữ. Chỉ số L-DLC là

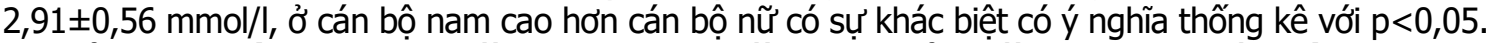

Bảng 3.7. Tình trạng thiếu Albumin huyêt thanh của đồi tượng nghiên cứu

\begin{tabular}{|c|c|c|c|c|}
\hline \multicolumn{2}{|c|}{ Thông tin } & \multirow{2}{*}{$\frac{\text { Số lượng }}{4}$} & Tỷ lệ \% & $\mathbf{p}$ \\
\hline Nhóm tuổi & $\leq 65$ tuối $(n=426)$ & & 0,9 & \multirow{2}{*}{$>0,05$} \\
\hline Nhom tuol & $65-80$ tuối $(n=374)$ & 5 & 1,3 & \\
\hline \multirow[t]{2}{*}{ Giới tính } & $\operatorname{Nam}(n=663)$ & 6 & 0,9 & \multirow[t]{2}{*}{$>0,05$} \\
\hline & $\begin{array}{l}\text { Nữ }(n=137) \\
=800)\end{array}$ & $\begin{array}{l}3 \\
9\end{array}$ & $\frac{2,2}{1,1}$ & \\
\hline
\end{tabular}

Kết quả bảng 3.7 cho thấy tỷ lệ thiếu Albumin huyết thanh ở cán bộ từ 65 tuối trở xuống là 0,9\% thấp hơn nhóm cán bộ trên 65 tuối là 1,3\%, tỷ lệ thiếu Albumin ở nhóm cán bộ nam là $0,9 \%$ cao hơn nhóm cán bộ nữ là 2,2\%, sự khác biệt không có ý nghĩa thống kê với p>0,05.

Bảng 3.8. Tình trạng rôi loạn lipid máu theo giới và nhóm tuối

\begin{tabular}{|c|c|c|c|c|}
\hline \multirow{2}{*}{ Nhóm tuổi } & \multicolumn{1}{|c|}{ Thông tin } & Số lượng & Tỷ lệ \% & \multirow{2}{*}{ P } \\
\cline { 2 - 4 } & $65-80$ tuối $(n=426)$ & 236 & 55,4 & \multirow{2}{*}{$<0,05$} \\
\hline \multirow{2}{*}{ Giới tính } & Nam $(n=663)$ & 233 & 62,3 & \multirow{2}{*}{$>0,05$} \\
\cline { 2 - 4 } & Nữ $(n=137)$ & 393 & 59,3 & \\
\hline \multicolumn{2}{|c|}{ Chung $(n=800)$} & 76 & 55,5 & \\
\hline
\end{tabular}


Kết quả bảng 3.8 cho thấy tỷ lệ cán bộ có rối loạn lipid máu là $58,6 \%$, trong đó tỷ lệ rối loạn lipid máu ở cán bộ từ 65 tuối trở xuống chiểm $55,4 \%$ thấp hơn tỷ lệ rối loạn lipid máu ở cán bộ trên 65 tuổi là $62,3 \%$, sự khác biệt với $p<0,05$. Tỷ lệ rối loạn lipid máu ở cán bộ nam là $59,3 \%$ cao hơn cán bộ nữ là 55,5\%, sự khác biệt không có ý nghĩa thống kê.

\section{BÀN LUÂ̂N}

Tỷ lệ thừa cân, béo phì chung là $14,4 \%$. Tỷ lệ thừa cẩn ở nữ giới là $7,3 \%$ thấp hớn nam là $15,8 \%$, sư khác biêt có ý nghĩa thống kê với $p<0,05$. Kết quả nghiên cứu cho thấy tî̉ lệ thừa cân, béo phì ở nam giới cao gấp đôi nữ giới, sự khác biệt này có ý nghĩa thống kê, do đó cần quan tầm kiểm soát cân nặng đặc biệt là ở những đối tượng nam giới này. Có thể một trong những nguyên nhân gây nên tình trạng thừa cân béo phì này ở thói quen ăn uống, sinh hoạt, sử dụng bia rượu ở những đối tượng nam giới. Kết quả nghiên cứu của chúng tôi cao hơn so với một số nghiên cứu trước đây. Tại Việt Nam, theo điểu tra của Viện Dinh dưỡng Quốc gia năm 2006 có gần 7 triêuu người bi thừa cân, béo phì, chiếm hơn $8 \%$ dân số. Nghiên cứu của Viện Dinh dưỡng thực hiện năm 2008 ở khu vực nông thôn cho biết tỷ lệ BMI $\geq 25$ là 9,6\%. Tai các thành phố lớn, tình trạng thừa cân, béo phì lên tới $30 \%$ [6]. Quan sát một số nhóm đối tượng dân cư, nghề nghiệp có tỳ lệ mắc thừa cân béo phì cao hơn nhiều so với trung bình của quốc gia, lên đến 40\%. Điều đáng lo ngại hơn là khi phân tích kết quả các giám sát dinh dưỡng cho thấy tuổi của người mắc thừa cân béo phì ngày càng trẻ hóa và béo phì mức độ nặng ngày càng gia tăng [7].

Kết quả bảng 3.4 cho thây tỷ lệ cán bộ có nguy cơ sức khỏe tính theo chỉ số vòng eo/vòng mông chiếm $43,1 \%$, trong đó cán bộ nữ là $44,5 \%$ cao hơn cán bộ nam là 42,8\%, sự khác biệt này không có ý nghĩa thống kê với $p>0,05$. Tỷ lệ WHR cao song hành cùng với tỷ lệ béo phì được đánh giá bằng chỉ số BMI ở Việt Nam cũng tưởng tự như ở các nước khác. Tỷ lệ này theo một nghiên cứu của Pakistan tại khu vực thành thị là $34 \%$ ở nam và $49 \%$ ở nữ, thừa cân béo phì đồng thời với tỷ lệ béo bụng (VE/VM) cao là $41 \%$ ở nam, $72 \%$ ở nữ và tăng tỷ lệ theo độ tuổi [1]. Béo bụng là một chỉ số được nhiêu nhà nghiên cứu quan tâm, được coi là dấu hiệu chỉ điểm tăng nguy cơ bệnh tim mạch hơn là toàn bộ khối mõ cơ thể [2], [3]. Khối mõ bụng có thể làm thay đổi rõ rệt toàn bộ mõ cơ thể hoặc BMI. Tỷ số vòng eo/vòng mông cao đã được chấp nhận như là một phương pháp lâm sàng để xác định có tích luỹ mõ ở bụng.

Kết quả bảng 3.5 dựa trên các tiêu chí đánh giá phân loại sức khỏe các cán bộ được nghiên cứu cho thấy tỷ lệ cán bộ sức khỏe loại $\mathrm{B} 1$ cao nhất chiếm tỷ lệ $88,9 \%$, loại $A$ chiếm $7,1 \%$, loại $B 2$ chiếm 3,2\%, loại $C$ chiếm $0,8 \%$, không có sự khác biệt về tình trạng sức khỏe của cán bộ nam và nữ với $p>0,05$. Sự đánh giá phân loại sức khỏe này cho biết thực trạng sức khỏe cán bộ, dự báo xu hướng tiến triển về sức khỏe để ban chăm sóc sức khỏe tỉnh có những cơ sở để chăm sóc sức khỏe cho các cán bộ được hiệu quả nhất.

Kết quả bảng 3.8 cho thấy tỷ lệ cán bộ có rối loạn lipid máu là $58,6 \%$, trong đó tỷ lệ rối loạn lipid máu ở cán bô từ 65 tuổi trở xuống chiếm $55,4 \%$ thấp hơn tỷ lệ rối loạn lipid máu ở cán bộ trên 65 tuổi là $62,3 \%$, sự khác biệt với $p<0,05$. Tỷ lệ rối loạn lipid máu ở cán bộ nam là $59,3 \%$ cao hơn cán bô nữ là $55,5 \%$, sự khác biêt không có ý nghĩa thống kê. Có sự khác biệt giữa tỷ lệ rối loạn lipid máu ở nhóm cán bộ từ 65 tuổi trở xuống thấp hơn nhóm từ 65 trở lên có thể giải thích rằng yếu tố tuổi tác cũng là một trong những nguyên nhân có thể gây ra sự khác biệt này.

Kết quả này so với kết quả nghiên cứu của Đỗ Đình Xuân và Trần Văn Long thực hiện ở 3 tỉnh đồng bằng bắc bô trên 630 người > 40 tuổi thì tỷ lệ hiện mắc các rối loạn lipid máu của chúng tôi thấp hơn vì trong nghiên cứu này có tới $70,4 \%$ có rối loạn lipid máu [8], hay tỷ lề này khi nghiên cứu trền bênh nhân có bênh lý tim mạch của Nguyễn Đào Dũng là $75,7 \%$, cao hơn so với kết quả của chúng tôi [5].

\section{KẾT LUÂN}

Tỷ lệ suy dinh dương chung ở cán bộ theo BMI là $0,6 \%$. Tỷ lệ thừa cân, béo phì là $14,4 \%$, tỷ lệ cán bộ có nguy cơ thừa cân béo phì là $43,1 \%$

- Nhóm cán bộ có sức khỏe phân loại B1 cao nhất chiếm tỷ lệ $88,9 \%$, loại $A$ chiếm $7,1 \%$, loại $B 2$ chiếm 3,2\%, loại $C$ chiếm $0,8 \%$.

- Chỉ số Albumin huyết thanh trung bình là $43,6 \pm 4,6 \mathrm{~g} / \mathrm{l}$; Protein huyết thanh trung bình là $70,0 \pm 8,1 \mathrm{~g} / \mathrm{l}$, Glucose máu trung bình là $6,7 \pm$ $1,5 \mathrm{mmol} / \mathrm{l}$. Chỉ số Cholesterol máu trung bình là 5,29 $\pm 0,66 \mathrm{mmol} / ;$ chỉ số Triglycerid máu trung

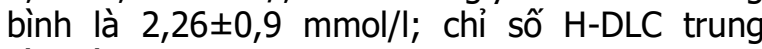
bình là $1,96 \pm 0,68(\mathrm{mmol} / \mathrm{l})$.

- Tỷ lệ thiếu Albumin huyết thanh chung là 1,1\%. Tỷ lệ cán bộ có rối loạn lipid máu là 58,6\%.

\section{TÀI LIÊU THAM KHẢO}

1. Barbara Dennis, Kalimuddin Aziz, and Lilin She (2006), "High rates of Obesity and 
Cardiovascular Disease risk factors in lower middle class community in Pakistan: the Metroville Health Study", J Pak Med Assoc. 56(6).

2. Harald J. Schneider, Heide Glaesmer, and Jens Klotsche (2007), "Accuracy of Anthropometric Indicators of Obesity to Predict Cardiovascular Risk", The Journal of Clinical Endocrinology \& Metabolism 92(2), pp. 589 -594.

3. Mabel Deurenberg-Yap, et al. (1999), "Manifestation of cardiovascular risk factors at low levels of body mass index and waist-to-hip ratio in Singaporean Chinese", Asia Pacific J Clin Nutr 8(3), pp. $177-183$.

4. WHO (2011), Global status report on noncommunicable diseases 2010, WHO press, Geneva, Switzerland.

5. Nguyê̂n Đào Dũng, Lê Quý Phúc, Võ Văn Lượng (2006), "Kháo sát rối loạn lipid máu ở bệnh nhân có bệnh lý tim mạch ", Kỷ yếu tóm tắt báo cáo khoa hơc - hội nghị khoa học tim mạch toàn quốc lần thứ XI, p. 63.

6. Viện Dinh dưỡng Quốc gia (2006)), Kết quả điểu tra thừa cân-béo phì và môt số yếu tố liên quan ở người Việt Nam 25-64 tuổi,, Đề tài nghiên cứu khoa hoc cấp Bộ.

7. Viên Dinh dưỡng Quốc gia (2012), Báo cáo tóm tắt tổng điều tra dinh dưỡng 2009-2010, Chiến lược quốc gia về dinh dưỡng tầm nhìn 20112020 và tầm nhìn đến năm 2030.

8. Đố Đình Xuân, Trân Văn Long(2009), "Khảo sát tình trang rối loạn lipid máu ở nhóm người trên 40 tuổi tại một số tỉnh thuộc đồng bằng Bắc Bộ", Tap chí y hoc thức hành. 662(5), pp. 52-54

9. WiHO (2003), Chế độ ăn, dinh dưỡng và dự phòng các bệnh mạn tính. Sách dịch- Viện Dinh dưỡng. Geneva., 170.

\section{HÌNH ẢNH CộNG HƯởNG TỪ TRONG CHẨN ĐOÁN PHÂN BIÊT U TINH BÀO VÀ U TẾ BÀO MẦM KHÔNG PHẢI U TINH BÀO}

\section{TÓM TẮT}

Muc tiêu: khảo sát đặc điểm và giá trị hình ảnh công hưởng từ (CHT) trong chẩn đoán phân biệt u tinh bào (UTB) và u tế bào mầm không phải u tinh bào (UTBMKPUTB). Phương pháp: thiết kế nghiên cứu cắt ngang mô tả. Tất cả 52 bệnh nhân u tế bà̀o mầm tinh hoàn (chia thành 2 nhóm theo giải phẫu bệnh: là 24 bệnh nhân UTB và 28 bệnh nhân UTBMKPUTB) được khảo sát CHT tinh hoàn tại bệnh viện Bình Dân từ 01/01/2019 đến 31/12/2020.Kết quả: đăc điểm hình ảnh trên $\mathrm{CHT}$ thường qui của nhóm UTB là: bắt thuốc đồng nhất $(79,17 \%)$; đông tín hiêu trên T1W $(95,83 \%)$, tín hiệu thấp trên T2W $(79,17 \%)$, có vách và bắt thuốc vách $(83,33 \%)$, đa số không hoại tử tạo nang $(79,17 \%)$ và không xuất huyết trong u $(95,83 \%)$. Ngược lại nhóm UTBMKPUTB có tính chất bắt thuốc không đồng nhất $(92,86 \%)$, tín hiệu không đồng nhất trên cả T1W $(60,71 \%)$ và T2W $(89,29 \%)$. Đa phần u nhóm này không có vách $(85,71 \%)$, có hoại tử tạo nang $(78,57 \%)$ và xuất huyết bên trong u $(60,71 \%)$. Có sự khác biệt về đặc điểm hình ảnh trên giữa hai nhóm $u$ tinh bào và UTBMKPUTB $(p=0,0001)$. Hình ảnh CHT giúp chẩn đoán phân biệt u tinh bào với UTBMKPUTB với độ nhạy 95,83\%, độ đặc hiệu 89,29\%, giá trị tiên đoán dương $88,46 \%$, giá tri tiên đoán âm $96,15 \%$ và độ chính xác $92,31 \%$. Kết luận: CHT có vai trò quan trong trong việc phân biệt u tinh bào và UTBMKPUTB với độ chính xác khá cao.

*Đại học Y Khoa Phạm Ngọc Thạch Chịu trách nhiệm chính: Nghiêm Phương Thảo Email: nghiemphuongthaoy2003@gmail.com Ngày nhận bài: 17.8.2021

Ngày phản biện khoa học: 12.10.2021

Ngày duyệt bài: 20.10.2021
Nghiêm Phương Thảo*, Võ Hưng Anh Thu**

Tư khóa: cộng hưởng từ, u tinh bào, u tế bào mầm không phải u tinh bào.

\section{SUMMARY \\ DIFFERENTIATION OF TESTICULAR SEMINOMA AND NONSEMINOMATOUS GERM CELL TUMOR ON MAGNETIC RESONANCE IMAGING}

Objective: To explore the utility of magnetic resonance imaging (MRI) for the differential diagnostic of testicular seminoma and nonseminomatous germ cell tumors (NSGCTs). Methods: descriptive crosssectional study design. The medical records from 52 patients (including 24 seminomas and 28 NSGCTs) that were examinated preoperatively with MRI and treated with urologic surgery at Binh Dan hospital between 01/01/2019 and 31/12/2020 were retrospectively reviewed. Results: Seminomas were more likely to have signal homogeneity $(79,17 \%)$ isointensity on T1-weighted imaging (T1WI) $(95,83 \%)$, hypointensity on T2-weighted imaging (T2WI) $(79,17 \%)$, and had wide obviously enhanced fibrovascular septa $(83,33 \%)$ without hemorrhagic $(95,83 \%)$ or cystic degeneration (79,17\%). Conversely, NSGCT was more likely to have a signal heterogeneity $(92,86 \%)$, mainly mixed signal on T1WI $(60,71 \%)$ and T2WI $(89,29 \%)$, most of them had no fibrovascular septa $(85,71 \%)$, and hemorrhagic or cystic degeneration was common in malignant NSGCT $(60,71 \%$ and $78,57 \%$, respectively). MRI showed that there were significant differences in signal homogeneity, T1WI signal intensity, T2WI signal intensity, fibrovascular septa, hemorrhagic or cystic degeneration between seminomas and NSGCTs $(p=0,0001)$. The sensitivity, specificity, positive predictive value, negative predictive value of MRI in differential diagnosing seminomas and NSGCTs were 